\title{
Enhanced focal adhesion assembly reflects increased mechanosensation and mechanotransduction at maternal- conceptus interface and uterine wall during ovine pregnancy
}

\author{
Robert C Burghardt ${ }^{1}$, James R Burghardt ${ }^{1}$, James D Taylor II $^{1}$, Adele T Reeder ${ }^{1}$, \\ Bar T Nguen ${ }^{1}$, Thomas E Spencer ${ }^{2}$, Kayla J Bayless ${ }^{3}$ and Greg A Johnson ${ }^{1}$ \\ Departments of ${ }^{1}$ Veterinary Integrative Biosciences and ${ }^{2}$ Animal Science, Texas A\&M University, College Station, \\ Texas 77843-4458, USA and ${ }^{3}$ Department of Molecular \& Cellular Medicine, Texas A\&M System Health Sciences \\ Center, College Station, Texas 77843-4458, USA
}

Correspondence should be addressed to G A Johnson; Email: gjohnson@cvm.tamu.edu

\begin{abstract}
The integrity of the fetal-maternal interface is critical for proper fetal nourishment during pregnancy. Integrins are important adhesion molecules present at the interface during implantation; however, in vivo evidence for integrin activation and focal adhesion formation at the maternal-conceptus interface is limited. We hypothesized that focal adhesion assembly in uterine luminal epithelium (LE) and conceptus trophectoderm (Tr) results from integrin binding of extracellular matrix (ECM) at this interface to provide increased tensile forces and signaling to coordinate utero-placental development. An ovine model of unilateral pregnancy was used to evaluate mechanotransduction events leading to focal adhesion assembly at the maternal-conceptus interface and within the uterine wall. Animals were hysterectomized on days 40, 80, or 120 of pregnancy, and uteri immunostained for integrins (ITGAV, ITGA4, ITGA5, ITGB1, ITGB3, and ITGB5), ECM proteins (SPP1, LGALS15, fibronectin (FN), and vitronectin (VTN)), cytoskeletal molecules (ACTN and TLN1), and a signal generator (PTK2). Focal adhesion assembly in myometrium and stroma was also studied to provide a frame of reference for mechanical stretch of the uterine wall. Large focal adhesions containing aggregates of ITGAV, ITGA4, ITGA5, ITGB1, ITGB5, ACTN, and PTK2 were detected in interplacentomal uterine LE and Tr of gravid but not non-gravid uterine horns and increased during pregnancy. SPP1 and LGALS15, but not FN or VTN, were present along LE and Tr interfaces in both uterine horns. These data support the idea that focal adhesion assembly at the maternal-conceptus interface reflects adaptation to increasing forces caused by the growing fetus. Cooperative binding of multiple integrins to SPP1 deposited at the maternal-conceptus interface forms an adhesive mosaic to maintain a tight connection between uterine and placental surfaces along regions of epitheliochorial placentation in sheep.

Reproduction (2009) 137 567-582
\end{abstract}

\section{Introduction}

Focal adhesions are dynamic macromolecular complexes comprised of heterodimeric transmembrane integrin receptors that connect extracellular matrix (ECM) proteins to the actin cytoskeleton, along with a diverse array of cell signaling intermediates (Sastry \& Burridge 2000, Wozniak et al. 2004, Larsen et al. 2006). Consequently, focal adhesions function to transmit force at cell adhesion sites and serve as signaling centers from which numerous intracellular pathways can regulate cell growth, proliferation, survival, gene expression, development, tissue repair, migration, and invasion. Studies in cultured cells indicate that the location, size, and specific protein components of focal adhesions are dependent upon the composition and rigidity of the ECM and the application of external or generation of internal mechanical forces to integrin-ECM connections (Katz et al. 2000, Galbraith et al. 2002). Furthermore, the force-dependent phosphorylation of multiple adaptor, cytoskeletal, and signaling proteins within focal adhesion complexes implies that focal adhesions sense and transduce mechanical forces (Vogel 2006). Recently, specific mechanosensory components of focal adhesions have been further resolved and associated with several multimodular ECM and cytoskeletal proteins that are tethered by their transmembrane integrin receptors. The conformations of these mechanosensory proteins are mechanically altered in response to force and generate cytoplasmic signals via phosphorylation (Vogel 2006). These conformation-dependent changes in sensors are transmitted to signal generators such as protein tyrosine kinase 2 (PTK2, also known as focal adhesion kinase $($ FAK)) in a process termed mechanotransduction, to activate intracellular signaling pathways (Giannone \& Sheetz 2006). 
Focal adhesions have been largely defined by their organization in cells plated on rigid, planar twodimensional (2D) matrices in vitro (Sastry \& Burridge 2000). However, small focal adhesion-like structures also develop in cultured cells grown in 3D ECM. These are termed '3D matrix adhesions,' and are accepted simulations of the in vivo condition (Cukierman et al. 2001). There is increasing evidence that 3D matrix adhesions are distinct from their 2D counterparts. Focal adhesions and 3D matrix adhesions that form in the presence of 2D and 3D ECM with varying biochemical and biophysical properties are known to give rise to distinct signals that result in different mechanosensory roles and cell behaviors (Cukierman et al. 2002, Geiger \& Bershadsky 2002). Indeed, Engler et al. (2006) have shown that increasing matrix stiffness directs human mesenchymal stem cell differentiation along disparate neuronal, muscle, or bone lineages. Although the former study indicates that mechanical stiffness in $2 \mathrm{D}$ can be transduced into an intracellular signal, relatively little is known about in vivo focal adhesions that assemble along cell surfaces in three dimensions within a more complex ECM (Wozniak et al. 2004).

The ability of focal adhesions to be maintained as stable structures depends upon the continuous application of local force, either exerted from the contractile machinery within the cell or from outside of the cell by application of external forces (Bershadsky et al. 2006). Smooth muscle adherens junctions are examples of large and highly ordered in vivo focal adhesions that assemble in muscle cells lining hollow organs in response to external forces (e.g., Eddinger et al. 2007). They are organized into linear strands of transmembrane $\alpha_{5} \beta_{1}$ integrin (heterodimeric ITGA5 + ITGB1 receptor) linking the ECM protein fibronectin (FN) with many of the cytoskeletal proteins and signaling molecules that assemble within cells upon integrin activation (Miyamoto et al. 1995). It is noteworthy that the development of these focal adhesions in smooth muscle cells lining the mammalian uterus (myometrium), increase as pregnancy progresses (Williams et al. 2005). This is associated with changes in endocrine signals and mechanical stretch of the uterine wall that lead to increased expression of ECM and hypertrophy of myometrial cells as the myometrium progressively adapts its compliance and contractility to expel a fetus at term (MacPhee \& Lye 2000, Li et al. 2007).

In contrast to the focal adhesions that develop in uterine myometria during pregnancy, the development of focal adhesions in vivo at the maternal-conceptus interface during implantation and placentation has not been described despite the fact that (a) integrins are the most extensively studied adhesion molecules involved in implantation, (b) that the uterine luminal surface contains a variety of ECM proteins (Aplin 1997, Burghardt et al. 1997, 2002, Kimber 2000, Lessey 2002, Johnson et al. 2003a, Armant 2005, Quenby et al. 2007), and (c) that cultured trophectoderm (Tr) and luminal epithelium (LE) cells from numerous species are capable of forming focal adhesions when placed in 2D matrices or when ECM-coated beads are deposited on the apical surfaces of these cell types (Parast et al. 2001, Johnson et al. 2001, Garlow et al. 2002, Coutifaris et al. 2005, Jaeger et al. 2005). Furthermore, the treatments that block integrin attachment have been shown to reduce the number of implantation sites in mice and rabbits (Illera et al. 2000, 2003). During the periimplantation period of pregnancy in sheep, integrins $\alpha_{v}, \alpha_{4}, \alpha_{5}, \beta_{1}, \beta_{3}$, and $\beta_{5}$ (ITGAV, ITGA4, ITGA5, ITGB1, ITGB3, and ITGB5) as well as the integrin-binding proteins, secreted phosphoprotein 1 (SPP1, also known as osteopontin) and galectin 15 (LGALS15) are present at the apical surfaces of both conceptus $\operatorname{Tr}$ and uterine LE (Gray et al. 2004); however, to our knowledge, there have been no reports describing the formation of focal adhesions in the endometrium in vivo during implantation or placentation in sheep or other mammals.

We hypothesized that mechanical forces generated at the maternal-conceptus interface during early implantation are minimal due to the small mass of the conceptus (embryo and associated extraembryonic membranes), and, therefore, do not result in the formation of easily detectable focal adhesions. However, mechanical forces at this interface increase with fetal and placental growth, as well as formation of fetal fluids, as pregnancy progresses, thereby stimulating the development of focal adhesions between $\operatorname{Tr}$ and LE cells as an adaptation to the three basic types of mechanical loading including increased tension, compression, and/or shear stress. In this study, we utilized a unilaterally pregnant sheep model to explore the role of focal adhesions as mechanosensors at the maternalconceptus interface during pregnancy. We also examined the development of focal adhesions in pregnant myometrium and stroma to provide a frame of reference for mechanical stretch of the uterine wall and to validate the reagents used to examine focal adhesions at the maternal-conceptus interface. We report evidence for the progressive development of large focal adhesions along the maternal-conceptus interface during placentation. These studies provide the first direct in vivo evidence of functional roles for integrins in signaling between conceptus and maternal tissues that reflect placental adaptations to increased mechanical loading that results from increased fetal growth as pregnancy advances.

\section{Results}

A number of integrin subunits (ITGAV, ITGA4, ITGA5, ITGB1, ITGB3, and ITGB5) have previously been identified at the apical surfaces of both ovine conceptus $\mathrm{Tr}$ and uterine endometrial LE cells during the periimplantation period (Johnson et al. 2001). Thus, integrin 
receptors $\alpha_{v} \beta_{3}, \alpha_{v} \beta_{1}, \alpha_{v} \beta_{5}, \alpha_{4} \beta_{1}$, and $\alpha_{5} \beta_{1}$ are potentially available for binding to the arginine-glycine-aspartic acid (RGD) and non-RGD containing ECM proteins at the maternal-conceptus interface. Preliminary immunofluorescence screening for ITGAV in sections of interplacentomal tissues obtained near the end of the first trimester of pregnancy of sheep (day 45) identified areas of intense apical punctate staining that appeared aggregate into dense deposits in single cells or small groups of cells. Mononuclear $\operatorname{Tr}$ cells also exhibited aggregates of the ITGAV subunit (Fig. 1).

We hypothesized that these aggregates of apical ITGAV subunit staining represent focal adhesions that are formed in response to increasing tensile or shear forces at the maternal-conceptus interface imposed by the size and/or weight of the growing embryo/fetus and associated extraembryonic membranes. To analyze pregnancy-associated changes in integrin subunit expression, a unilaterally pregnant ewe model (Fig. 2) was utilized to evaluate differences in apical integrin expression in the LE of gravid and non-gravid uterine horns as well as differences in placentomal and interplacentomal epithelial cells in the gravid horns at days 40,80 , and 120 of pregnancy. Furthermore, since induction of focal adhesions in uterine myometrium has a force-dependent component (MacPhee \& Lye 2000, Williams et al. 2005, Li et al. 2007, Shynlova et al. 2007), we first evaluated the timing and pattern of focal adhesion organization in uterine myometrium to provide an index of mechanosensory input in the form of stretch of the uterine wall imposed by the growing conceptus.

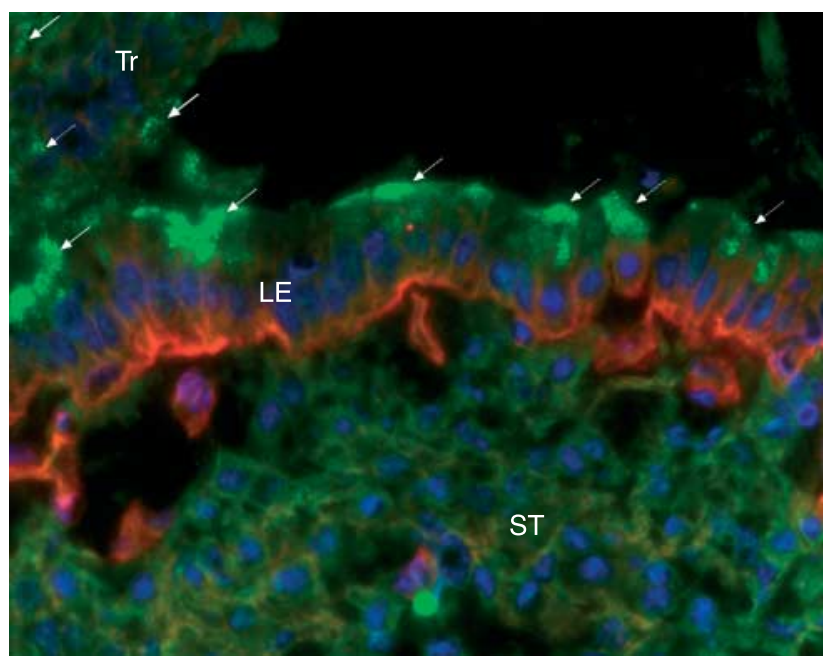

Figure 1 Immunofluorescence localization of the IGTAV $\left(\alpha_{v}\right)$ integrin in interplacentomal regions of the ovine uterus on day 45 of pregnancy. In this section, trophectoderm cells (Tr) have been mechanically separated from the LE. Note punctate IGTAV immunostaining (green) in both uterine luminal epithelial cells (LE) and $\operatorname{Tr}$ cells, which appears to coalesce into large deposits at the apical cell surfaces. The basal lamina of the LE is counterstained (red) and the nuclei are stained (blue) with DAPI. Width of field is $320 \mu \mathrm{m}$.

\section{Focal adhesion assembly in ovine myometrium}

Scattered punctate immunostaining for ITGA5 $\left(\alpha_{5}\right)$, which exclusively heterodimerizes with the $\beta_{1}$ integrin subunit, was detected at the surface of myometrial cells in the longitudinal and circular layers of both day 15 cyclic and pregnant sheep myometrium. Strands of focal adhesions developed at the surface of cells in the gravid horns by day 40 of pregnancy, and more highly ordered focal adhesions were present in day 80 and 120 myometrium (Fig. 3A). Identical temporal and highly ordered spatial immunostaining patterns were observed for the multimodular, mechanosensory ECM protein FN, and putative intracellular mechanosensory cytoskeletal proteins talin (TLN1) and vinculin (VCL; Fig. 3B), as well as $\alpha$-actinin (ACTN; data not shown). These data indicate that the mechanical stretch of the uterine wall that results from accumulation of fetal fluids in the allantois and amnion as well as growth of the fetus contributes sufficient continuous local force to maintain mechanosensory signals required to initiate development of highly ordered focal adhesions in uterine smooth muscle cells by day 40 of pregnancy. They also confirm the utility of the selected antibodies to localize focal adhesion constituents in ovine uterine tissues in a cell type known to develop focal adhesions in vivo. Subsequent results showing in vivo accumulation of focal adhesion proteins at the maternal-conceptus interface were realized using these antibodies.

\section{Integrin aggregation at the maternal-conceptus interface}

In contrast to the observations of integrin-staining patterns in uterine LE observed during the periimplantation period of pregnancy (Johnson et al. 2001), little apical immunostaining of ITGAV, ITGA4, ITGA5, ITGB1, ITGB3, and ITGB5 was detected in LE cells of caruncular and intercaruncular regions of non-gravid uterine horns on any of the days of pregnancy examined (Fig. 4A). Intense but intermittent immunostaining for ITGAV, ITGA4, ITGA5, ITGB1, and ITGB5, but not ITGB3, was detected along the apical surfaces of both LE and $\mathrm{Tr}$ cells in the interplacentomal region of gravid uterine horns (Fig. 4A), but not in the LE of the non-gravid uterine horn. The apical and punctuate distribution, intensity of signal, and expansive nature of the immunoreactivity are interpreted to result from engagement of integrin heterodimers with an ECM ligand and aggregated as components of large organized focal adhesions at the maternal-conceptus interface. It is noteworthy that while ITGB3 immunostaining was absent from the LE, intense staining of both ITGAV and ITGB3 was present in the subepithelial stroma compartment of interplacentomal endometrium indicative of the presence of the $\alpha_{v} \beta_{3}$ integrin heterodimer that was confirmed with a heterodimer-specific monoclonal 

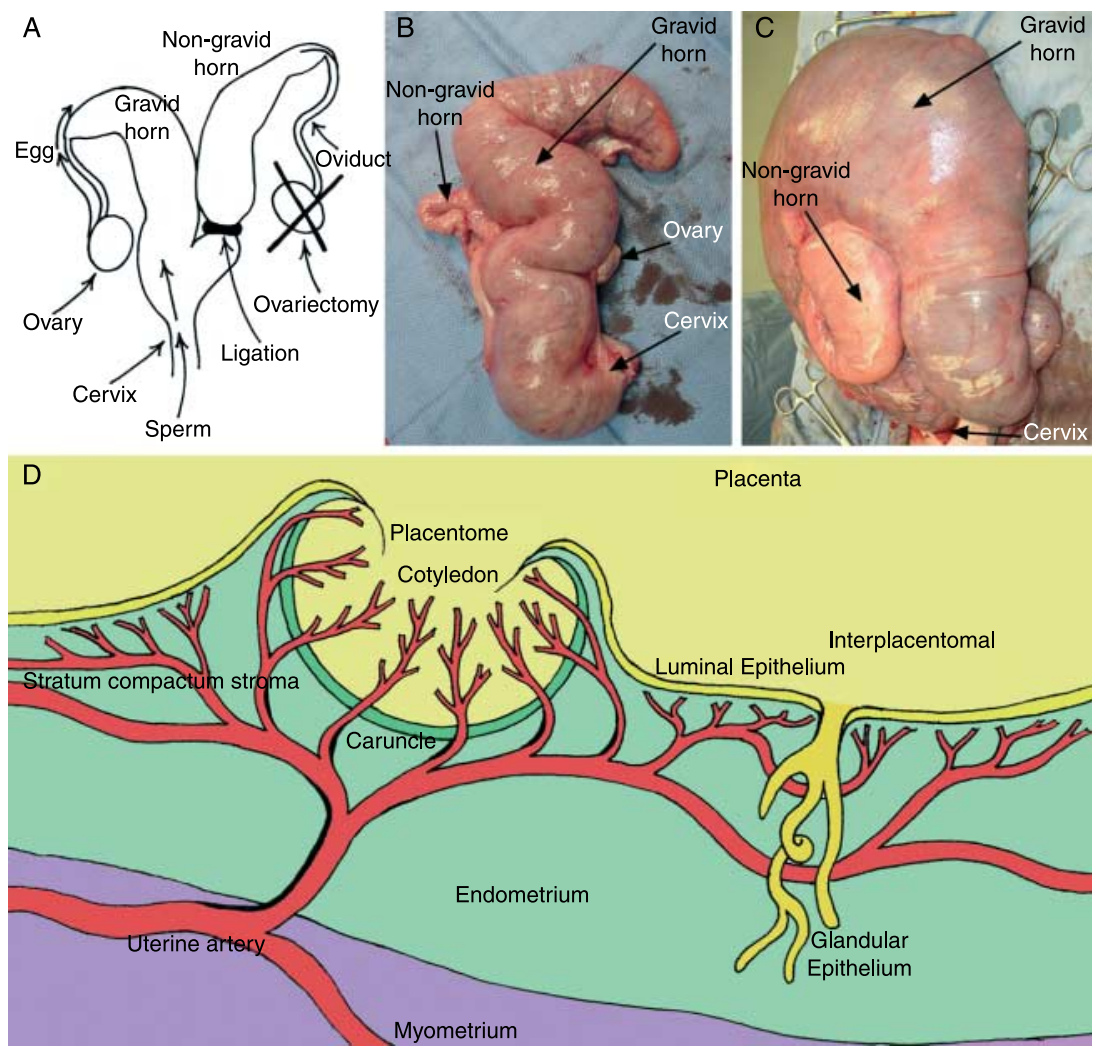

Figure 2 The unilaterrally pregnant ovine uterus. (A) A cartoon showing the surgical preparation of the unilaterally pregnant ovine uterus in which the ovary ipsilateral to the right uterine horn was removed and a double ligature placed at the base of the right uterine horn. (B and C) The unilaterally pregnant uterus at days 80 and 120 of pregnancy. Mechanical stretch of the uterine wall in gravid compared with non-gravid horns is evident; however, the non-gravid horn exhibits some mechanical stretching due to accumulation of uterine luminal secretions (histotroph) due to placement of the ligature at the base of the uterine horn. (D) A cartoon depicting the organization of the cotyledonary placenta of sheep. Placentomes are the major site of hematotrophic support for the fetus and consist of convoluted caruncular tissue from the maternal side and cotyledonary placental tissue from the fetal side. The interplacentomal portion of the placenta is formed by non-invasive apical-apical contacts between mononuclear $\mathrm{Tr}$ cells and uterine LE. antibody (Fig. 4B). The intensity of stromal ITGAV and ITGB3 staining was much greater in gravid compared with non-gravid uterine horns. Despite the intense staining, no large focal adhesion aggregates similar to LE and Tr staining was observed (Fig. 4B). Rather, a delicate punctate pattern of staining was detected that more closely resembles 3D matrix adhesions of cultured cells grown in a 3D ECM. None of the other integrin subunits examined exhibited significant staining in stroma. Analysis of integrin subunits within the placentomes (Fig. 4A) identified a reduced and more diffuse staining pattern for ITGAV, ITGA4, ITGA5, ITGB1, ITGB3, and ITGB5 than was detected in interplacentomal regions, with rare integrin subunit aggregates detected. Immunostaining varied among the integrins within placentomes. ITGAV and ITGB3 were expressed throughout the caruncular stroma, ITGAV and ITGB1 were present in the caruncular vasculature, and ITGA4 and ITGB5 expression was low to undetectable in placentomes.

Figure 5 shows a low magnification view immunostaining for the ITGAV subunit at the maternal-conceptus interface, which is equally representative of other subunits including ITGA4, ITGA5, ITGB1, and ITGB5 (data not shown). The intensity and distribution of each of the subunits increased as pregnancy advanced. Although focal adhesions were present over a small percentage of the LE and Tr cells on day 40 and was organized into clusters ranging from 30 to $80 \mu \mathrm{m}$, the size of these structures increased over time exceeding several millimeters of LE and Tr apical surfaces. Extensive focal adhesions were seen along the majority of the fetal-maternal interface by day 80 , and this pattern was maintained through day 120 of pregnancy.

\section{ACTN and TLN1 aggregation at the maternal-conceptus interface}

Analysis of focal adhesion-associated cytoskeletal proteins, TLN1 and ACTN, identified ACTN as the predominant actin-binding protein associated with integrin subunits in interplacentomal regions of the maternal-conceptus interface. The accumulation of ACTN immunostaining and the progressive increase with pregnancy were comparable with that of the ITGAV, ITGA4, ITGA5, ITGB1, and ITGB5 subunits (Figs 5 and $6 \mathrm{~A})$, suggesting recruitment of ACTN during assembly of mature focal adhesions to serve as a cytoplasmic mechanosensor. By contrast, apical TLN1 immunostaining was relatively low in both $\mathrm{LE}$ and $\operatorname{Tr}$ (data not shown).

While ACTN is associated with the cytoplasmic tail of $\beta$-integrin subunits in focal adhesions, it is also associated with the zonula adherens of epithelial cells in association with E-cadherin $(\mathrm{CDH} 1)$. Zonula adherens-associated ACTN protein was clearly evident and was the only ACTN immunostaining detected on day 15 

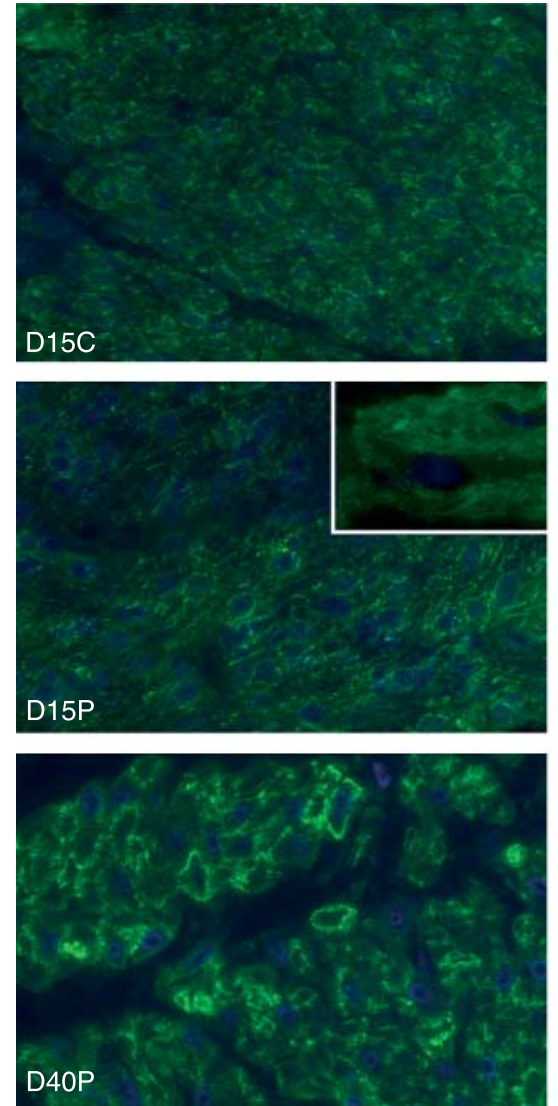

B
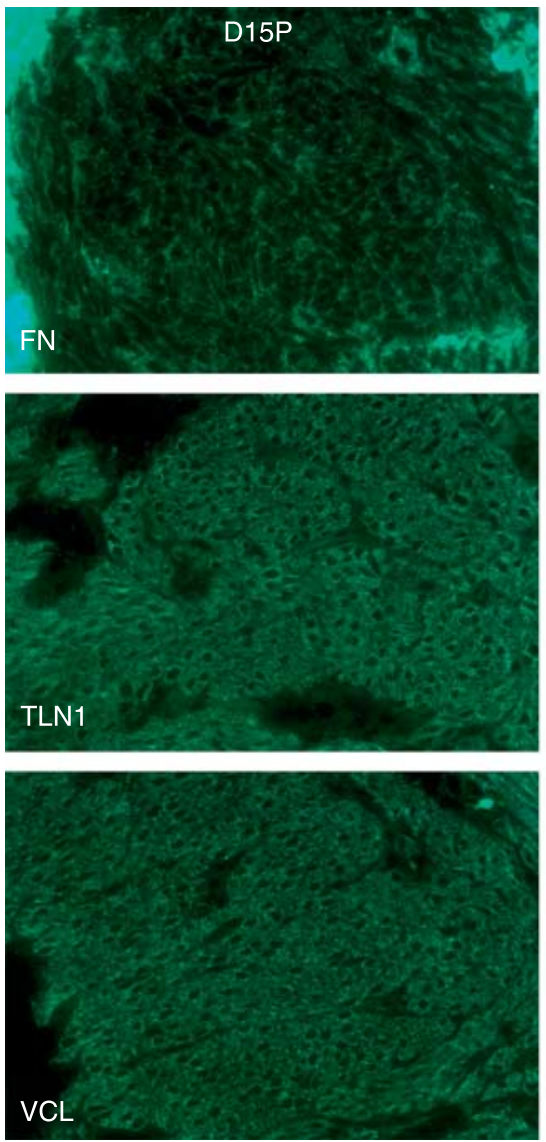
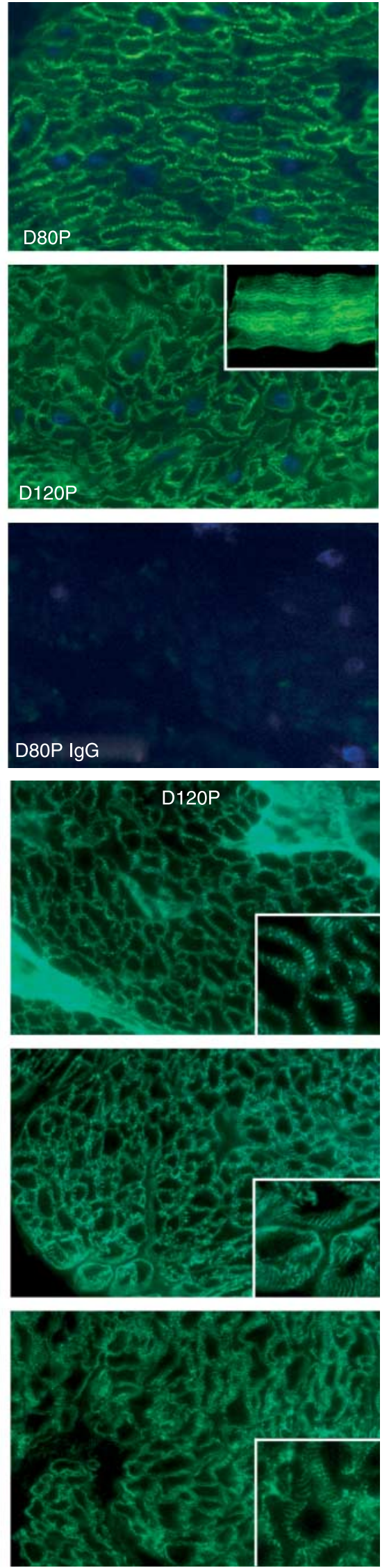

Figure 3 Development of focal adhesions in sheep myometrium. (A) Immunostaining for IGTA5 $\left(\boldsymbol{\alpha}_{5}\right)$ on day 15 of the estrous cycle and days $15,40,80$, and 120 of pregnancy. Note the development of linear strands of focal adhesions that appear as regularly distributed spots at the myometrial cell surface present in some cells on day 40 and which are present and highly ordered on all myometrial cells by day 80 and 120 of pregnancy. Insets provide for comparison longitudinal surface views of myometrial cells early and late in pregnancy. (B) Comparison of pregnancy day 15 and 120 immunostaining for the ECM protein $\mathrm{FN}$ and cytoplasmic focal adhesion proteins TLN1 (talin) and VCL (vinculin). Insets provide a higher magnification view of the highly ordered nature of these proteins associated with focal adhesions. Width of each field is $540 \mu \mathrm{m}$; width of field of insets is $240 \mu \mathrm{m}$. 
A
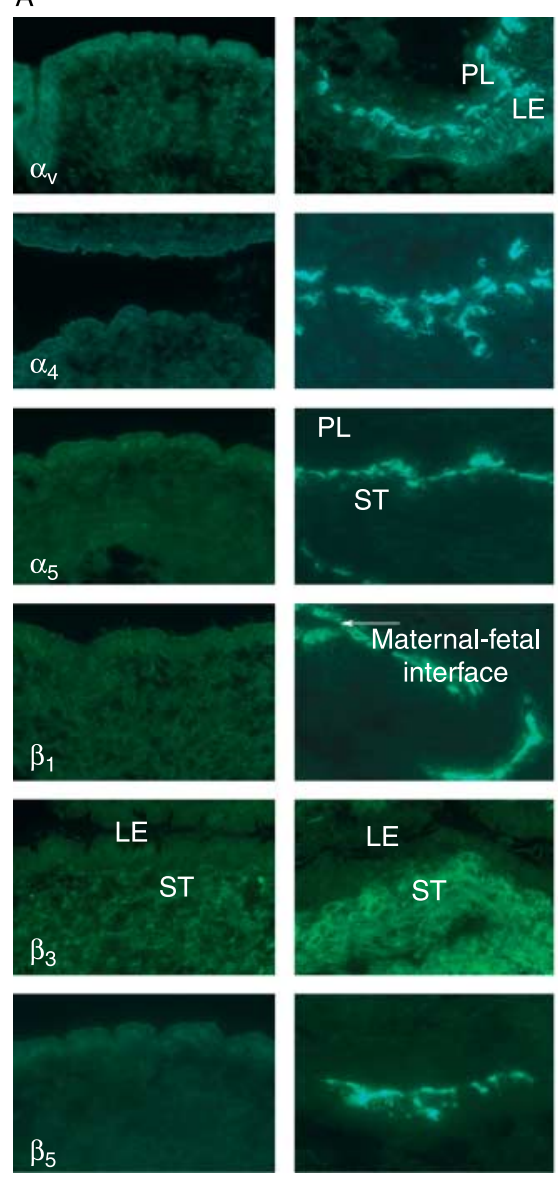

B
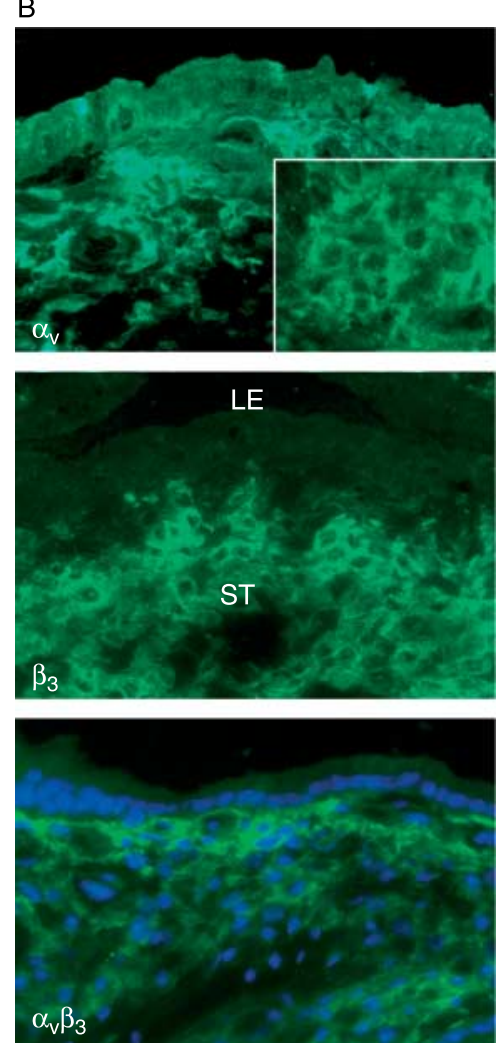
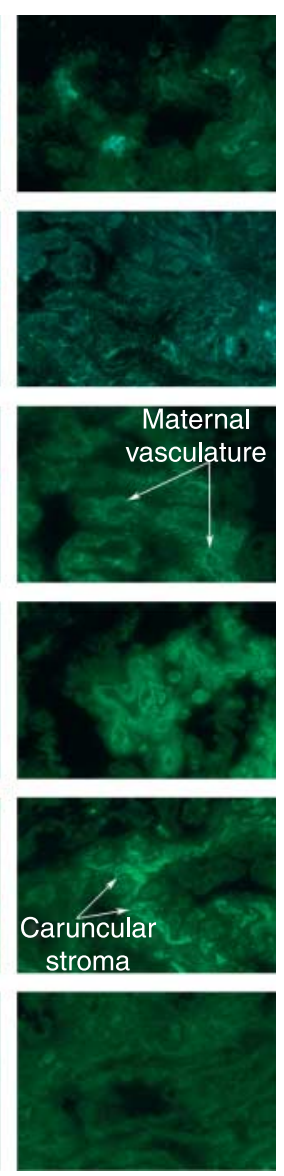

of the estrous cycle and pregnancy as well as in nongravid uterine horns (Fig. 6A). However, ACTN immunostaining became increasingly distributed across the apical LE surface after day 40. Therefore, to determine whether the progressive change in ACTN staining pattern resulted from reorganization of zona adherens and $\mathrm{CDH} 1 ; \mathrm{CDH} 1$ was localized in the same sections with ITGAV (Fig. 6B). Costaining of $\mathrm{CDH} 1$ and IGTAV indicated $\mathrm{CDH} 1$ associated with the apical junctional complex was not altered, despite the formation of apical focal adhesions containing ITGAV within LE or mononuclear Tr cells (Fig. 6B).

\section{SPP1 and LGALS15 are prominent ECMs at the maternal-conceptus interface}

Analysis of potential integrin-binding ECM mechanosensors available to sequester integrins and facilitate focal adhesion assembly was undertaken. Immunostaining for SPP1, LGALS15, FN, and vitronectin (VN) was performed in gravid and non-gravid horns of unilaterally pregnant sheep. No appreciable immunostaining for either $\mathrm{FN}$ or VN was observed at the apical surface of LE or Tr in either uterine horn. A progesterone-induced $45 \mathrm{kDa}$ form of SPP1 (detected with amino-terminal anti-SPP1 antibody, LF-124) that promotes greater cell attachment than the full-length $70 \mathrm{kDa}$ protein (Agnihotri et al. 2001) has previously been shown to be abundantly expressed along the entire uterine-placental interface (including placentomal and interplacentomal regions) through day 120 of pregnancy (Johnson et al. 2000, 2003 b). Immunostaining of the unilaterally pregnant uterus confirmed that the 45 kDa SPP1 was most abundant at the interface between uterus and placenta in gravid horns and was less abundant at the apical surface of non-gravid horns (Fig. 7).

Figure 4 Immunofluorescence analysis of integrin subunit proteins in frozen sections of sheep endometrium from unilaterally pregnant animals on day 80 of pregnancy. (A) ITGAV, ITGA4, ITGA5, ITGB1, ITGB3, and ITGB5 $\left(\alpha_{v}, \alpha_{4}, \alpha_{5}, \beta_{1}, \beta_{3}\right.$ and $\left.\beta_{5}\right)$ are compared in nongravid (left panel) and gravid uterine horns with gravid horns containing interplacentomal (middle panel) and placentomal regions (right panel). The center column emphasizes differences in interplacentomal LE versus stromal staining. Note that intense immunostaining for ITGAV, ITGA4, ITGA5, ITGB1, and ITGB5, but not ITGB3, is present at the apical epithelial surfaces of the interplacentomal regions of gravid horns. Little integrin immunostaining was observed in non-gravid uterine horns. Placentomal staining was greater than non-gravid uterus; however, integrin subunit aggregates were rarely detected. Placentomal ITGAV and ITGB3 were expressed throughout the caruncular stroma, ITGAV and ITGB1 were present in the caruncular vasculature, and ITGA4 and ITGB5 expression was low to undetectable. (B) Higher magnification imaging of ITGAV and ITGB3 proteins and the $\alpha_{v} \beta_{3}$ integrin heterodimer in uterine stroma. Inset shows an example of the delicate punctate pattern of stromal integrin staining that resembles $3 \mathrm{D}$ matrix adhesions of cultured cells grown in a $3 \mathrm{D} \mathrm{ECM.} \mathrm{LE,} \mathrm{luminal}$ epithelium; ST, stroma; PL, placental membranes. Width of each panel is $540 \mu \mathrm{m}$. 

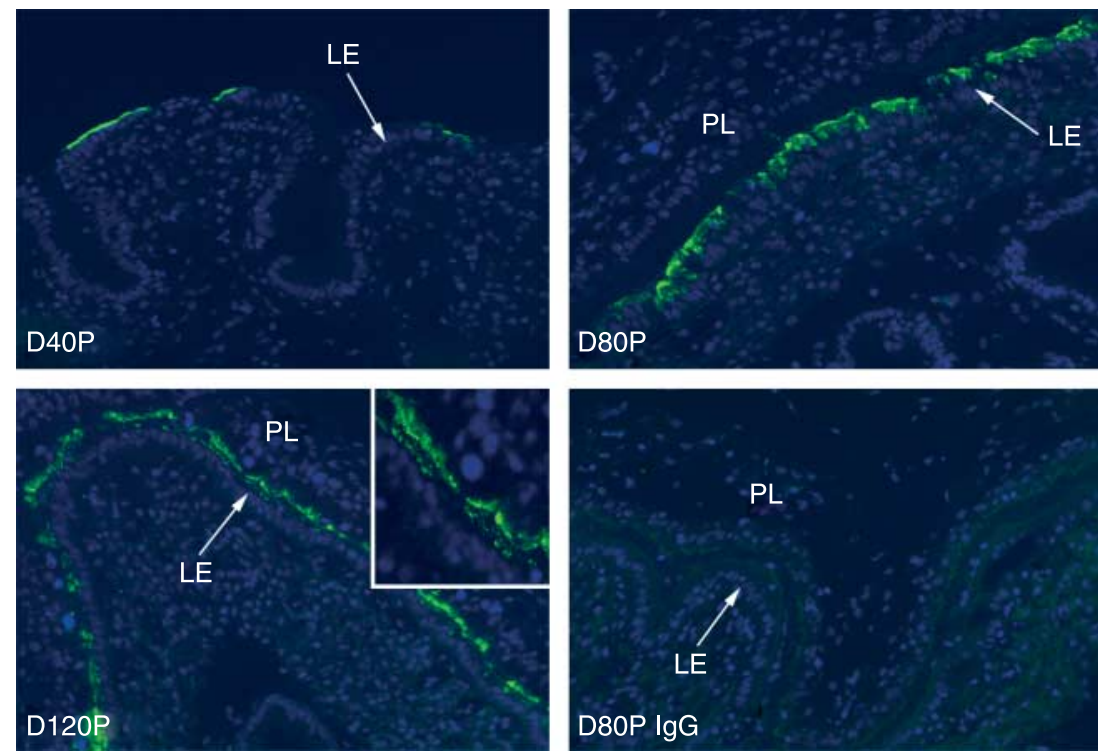

Figure 5 Immunofluorescence analysis of the ITGAV subunit in the interplacentomal region from the gravid horn of unilaterally pregnant sheep on days 40,80 , and 120 of pregnancy. Identical patterns were observed when staining for ITGA4, ITGA5, ITGB1, and ITGB5. Note the increased apical staining along the length of the maternal (LE)/placental (PL) interface with advancing pregnancy. Inset shows higher magnification view of apical staining in luminal epithelium and trophectoderm cells. Width of each field is $970 \mu \mathrm{m}$; width of field of inset is $240 \mu \mathrm{m}$.
Another recently identified progesterone-induced member of the galectin family, LGALS15, which is found in uterine histotroph (Gray et al. 2004) and capable of inducing focal adhesions in 2D cultures (Farmer et al. 2008), was detected within and at the apical surface of LE in the non-gravid horn and within the LE and superficial glandular epithelium of interplacentomal endometrium from gravid horns. The majority of LGALS15 immunostaining was sequestered within the $\mathrm{Tr}$ in gravid uterine horns (Fig. 7).

It is noteworthy that full-length SPP1 (detected with the carboxy terminal anti-SPP1 antibody, LF-123) along with $\mathrm{VN}$ and $\mathrm{FN}$ (but not LGALS15) immunostaining were all detected in the subepithelial stroma of both gravid and non-gravid uterine horns by day 40, although the intensity of staining, which was similar to that of the ITGAV and ITGB3 integrin subunits and the $\alpha_{v} \beta_{3}$ integrin heterodimer, was much higher in the gravid horn (Fig. 7). Staining intensity reached maximal levels by day 80 and remained high through day 120 . Each of these ECM proteins, which are ligands for the $\alpha_{v} \beta_{3}$ receptor, appear to be spatially and temporally coexpressed with $\alpha_{v} \beta_{3}$ (compare Figs 4B and 7) in a pattern that resembles 3D matrix adhesions of cultured cells grown in a 3D ECM.

\section{PTK2, a signal generator, is associated with mechan- osensors at the maternal-conceptus interface}

PTK2 (also known as FAK) becomes clustered into focal adhesions to enhance autophosphorylation at Y397 (pPTK2 or pFAK); this process is a key component of mechanotransduction at focal adhesions responsible for outside-in signal generation (reviewed in Wozniak et al. 2004). Immunofluorescence analysis identified pPTK2 in a temporal and spatial pattern similar to that observed for other key mechanosensory components of focal adhesions including ITGA4, ITGAV, ITGA5, ITGB1, and ITGB5 integrins, ACTN, TLN1, and SPP1 along the apical surfaces of both LE and $\operatorname{Tr}$ cells in the interplacentomal region of the gravid horn (Fig. 8). pPTK2 fluorescence in the subepithelial stroma of interplacentomal regions of gravid horns was barely detectable. No pPTK2 immunostaining was detected in non-gravid uterine LE or stromal tissue. The codistribution of pPTK2 with SPP1, ITGA4, ITGAV, ITGA5, ITGB1, ITGB5, ACTN, and, to a lesser extent, TLN1 suggests that the latter components come together to facilitate integrin clustering, leading to PTK2 phosphorylation.

\section{Discussion}

Focal adhesions, the hallmark of activated integrins, are prominent structures of cells grown in culture; however, they are rarely observed in vivo. Our objective was to investigate the development of in vivo focal adhesions in uterine and placentomal tissues as the uterine wall adapts to both endocrine signals and mechanical stretch imposed by the growing fetus. We examined three different tissue-level compartments of the pregnant ovine uterus, including the interacting endometrial LE and Tr epithelia, subepithelial stroma, and myometrium. Each of these layers is distinct with respect to the composition and 3D organization of the ECM. Smooth muscle cells in the uterus, like the subepithelial stromal fibroblasts, are exposed on all surfaces to the surrounding 3D matrix, whereas regional differences in the 3D matrix surrounding epithelial cells, i.e., basal, lateral, and apical surfaces, are responsible for promoting normal polarity and differentiation (Roskelley \& Bissell 1995). The results of the present studies indicate that integrin-ECM 

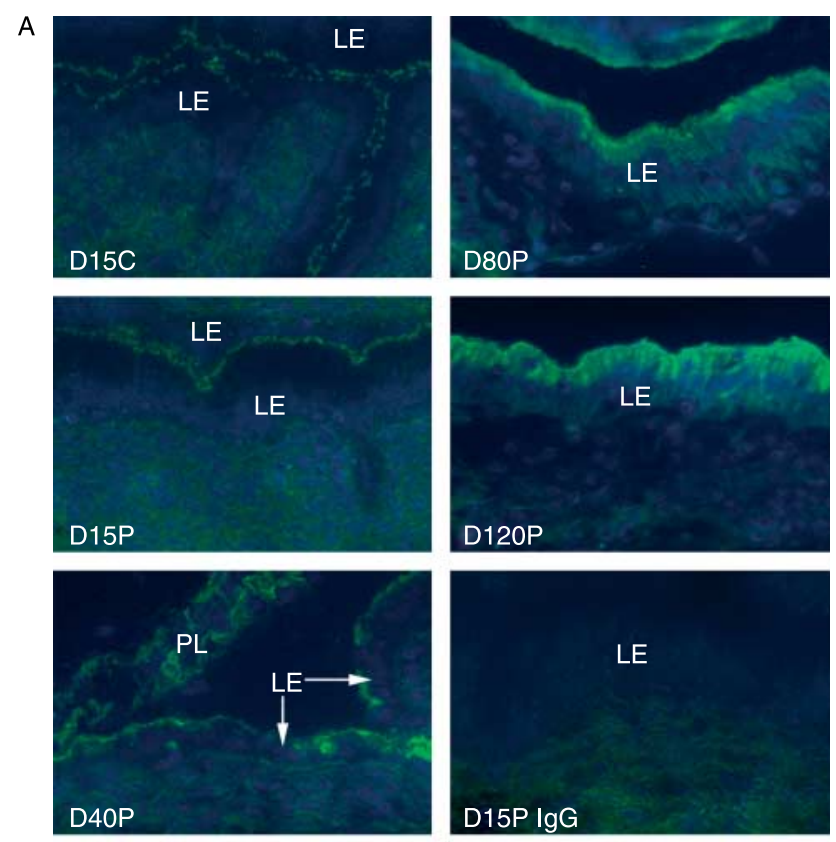

B
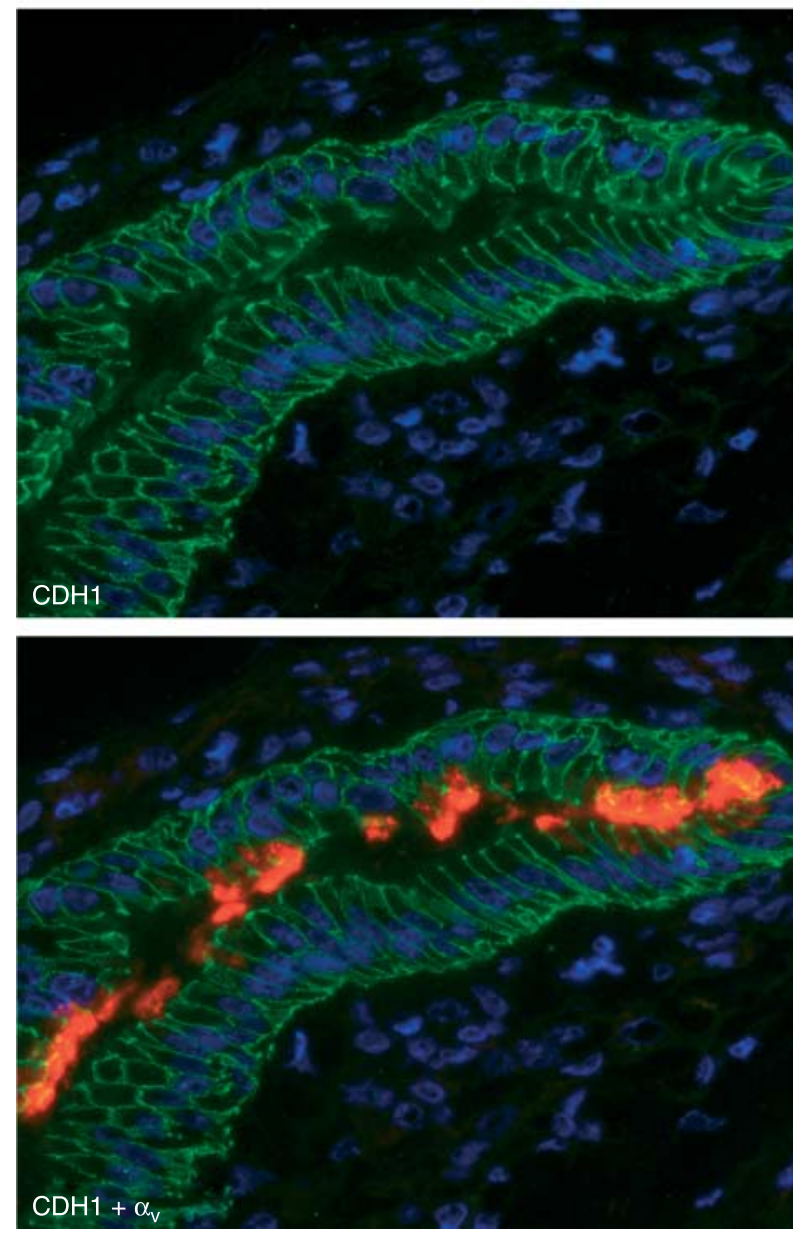

interactions are prominent throughout the pregnant ovine uterus, and that large focal adhesion complexes form and increase at the maternal-conceptus interface and between myometrial cells to accommodate increased application of mechanical forces in these tissues. Uterine stromal cells, on the other hand, exhibit upregulation of more diffuse focal adhesions that resemble 3D matrix adhesions during pregnancy.

\section{Focal adhesion assembly in uterine myometrial cells}

Focal adhesions in smooth muscle tissue, particularly in hollow organs such as the colon, are maintained as stable structures due to continuous application of local force from within and outside of the cell as changes in lumen diameter put great strain on intercellular connections (Bershadsky et al. 2006). By contrast, highly organized focal adhesions in myometrial cells from the rodent uterus are transient and restricted to a period during late pregnancy when both hormones of pregnancy and mechanical stretch upregulate the expression of the ECM mechanosensor FN (Shynlova et al. 2004) and other focal adhesion constituents, including the $\alpha_{5} \beta_{1}$ integrin receptor and its ECM mechanosensory ligand FN, the cytoskeletal mechanosensors TLN1 and ACTN, and signal generators including PTK2 and activated MAPK1 (MacPhee et al. 2001, Williams et al. 2005, Li et al. 2007, Shynlova et al. 2007). These changes contribute to firm linkage between cytoskeletal proteins within myometrial cells and the ECM that contributes to contractile activity sufficient to expel term fetuses at labor. Focal adhesion signaling is then rapidly terminated following labor (MacPhee \& Lye 2000).

The present studies indicate that a similar process of focal adhesion organization takes place in sheep myometrium. Focal adhesions begin to assemble during the first trimester of pregnancy, significantly earlier than rodents, and the magnitude and organization of these focal adhesions continue to increase concurrently with increasing fetal growth. Therefore, mechanical stretch of the uterine wall resulting from accumulation of fluids in the allantois and amnion and growth of the fetus contributes sufficient continuous local force by day 40 of pregnancy to initiate the development of focal adhesions in myometrial cells.

\footnotetext{
Figure 6 Immunofluorescence analysis of ACTN ( $\alpha$-actinin) in frozen sections of ovine endometria. (A) ACTN protein expression from day 15 of the estrous cycle and days 15, 40, 80, 120, and 140 of pregnancy. Note that ACTN is exclusively associated with zona adherens in LE of cyclic endometrium, but is reorganized into aggregates in the gravid horn. The pattern of ACTN immunostaining in interplacentomal endometrium during pregnancy was comparable with that of the ITGAV, ITGA4, ITGA5, ITGB1, and ITGB5 subunits. Width of each field is $540 \mu \mathrm{m}$. (B) Immunofluorescence costaining of $\mathrm{CDH} 1$ (green) and ITGAV (red) at the maternal-conceptus interface of day 40 of pregnancy in interplacentomal regions of the uterus. Width of each field is $540 \mu \mathrm{m}$.
} 

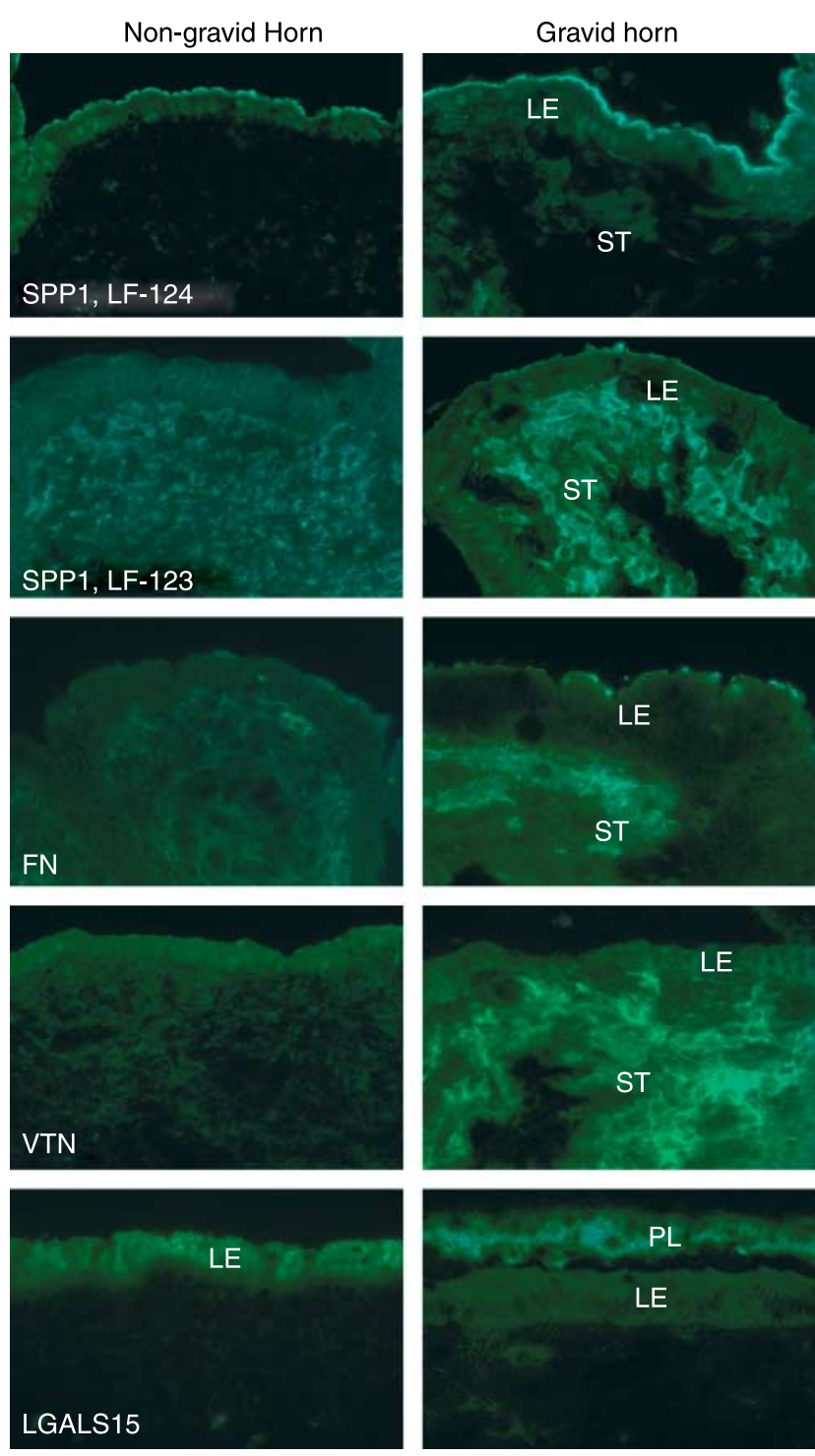

Figure 7 Immunofluorescence analysis of ECM proteins SPP1 (osteopontin), FN (fibronectin) VTN (vitronectin), and LGALS15 in gravid and non-gravid uterine horns of day 40 unilaterally pregnant sheep. A 45 kDa form of SPP1 (LF-124 staining) is abundantly and continuously expressed along the maternal-conceptus interface throughout pregnancy. A 70 kDa full-length SPP1 (LF-123 staining) FN, and VTN are upregulated in endometrial stroma of the gravid horn. Width of each field is $540 \mu \mathrm{m}$.

\section{Integrin and ECM expression in the uterine subepithelial stroma}

We previously reported that the subepithelial stroma of sheep undergoes extensive remodeling during pregnancy that is associated with the upregulation of a number of cytoskeletal proteins (desmin, vimentin, and actin, alpha 2, smooth muscle, aorta (ACTA2)) within myofibroblast-like stromal cells and alterations in the ECM that includes upregulation of SPP1 protein by day 35 of pregnancy (Johnson et al. 2003b, 2003c). Increases in ECM and incorporation of ACTA2 into stress fibers significantly augment the contractile activity of fibroblastic cells and are the hallmarks of connective tissue remodeling (Hinz 2007). This stromal remodeling process exhibits properties that resemble a decidualization-like response despite the absence of invasive implantation in sheep. In the present study, we extend previous observations to show that stromal remodeling includes a dramatic upregulation of the $\alpha_{v} \beta_{3}$ integrin, SPP1, FN, and VTN in stroma of gravid horns compared with the non-gravid horns of unilaterally pregnant sheep. Increased expression in gravid horns implies a contribution of conceptus and/or mechanical signals to this response. Furthermore, the diffuse spatial pattern of each of these proteins is similar and suggests their organization in 3D matrix adhesions that develop in a mechanically stressed environment. It is noteworthy that myofibroblast- and ECM-rich granulation tissue formed during wound closure exhibits three to five times greater stiffness than normal stromal tissue (Rehfeldt et al. 2007). However, despite the increased stiffness of the 3D stromal ECM, it is still far lower than a planar 2D matrix (Cukierman et al. 2002).

The stromal $\alpha_{\mathrm{v}} \beta_{3}$ receptor can bind VTN, FN, and the full-length $70 \mathrm{kDa}$ form of SPP1, which is in contrast to the $45 \mathrm{kDa}$ SPP1 form present at the maternal-conceptus interface (Johnson et al. 2003c). The significance of differences in distribution of SPP1 protein forms with respect to ECM rigidity are discussed in a subsequent section. We hypothesize that, similar to myometrium, the endometrial stromal compartment responds to the mechanical forces of pregnancy; however, because this connective tissue matrix is more strain shielded due to cross-linking of ECM, it exhibits lower rigidity than that surrounding myometrial cells or in the ECM at the maternal-conceptus interface. Therefore, more diffuse 3D focal adhesions, reminiscent of those observed for in vitro 3D ECM, appear to be formed between $\alpha_{v} \beta_{3}$ and SPP1 and VTN.

\section{Integrin aggregation at the maternal-conceptus interface}

This is the first report of progressive in vivo development of large aggregations of focal adhesion-associated proteins that we interpret to be 3D focal adhesions at the maternal-conceptus interface in any species, despite the fact that integrins are considered to be the dominant adhesion molecules involved in the implantation adhesion cascade in mammals (reviewed, Aplin 1997, Burghardt et al. 2002, Lessey 2002). By day 40 of pregnancy in sheep, the punctate apical surface staining of integrin receptor subunits identified in peri-implantation uterine LE and conceptus $\operatorname{Tr}$ (Johnson et al. 2001) is replaced by scattered large aggregates of ITGAV, ITGA4, ITGA5, ITGB1, and ITGB5 subunits in interplacentomal LE and Tr cells. Integrin aggregates were observed only in gravid uterine horns of unilaterally pregnant sheep, 

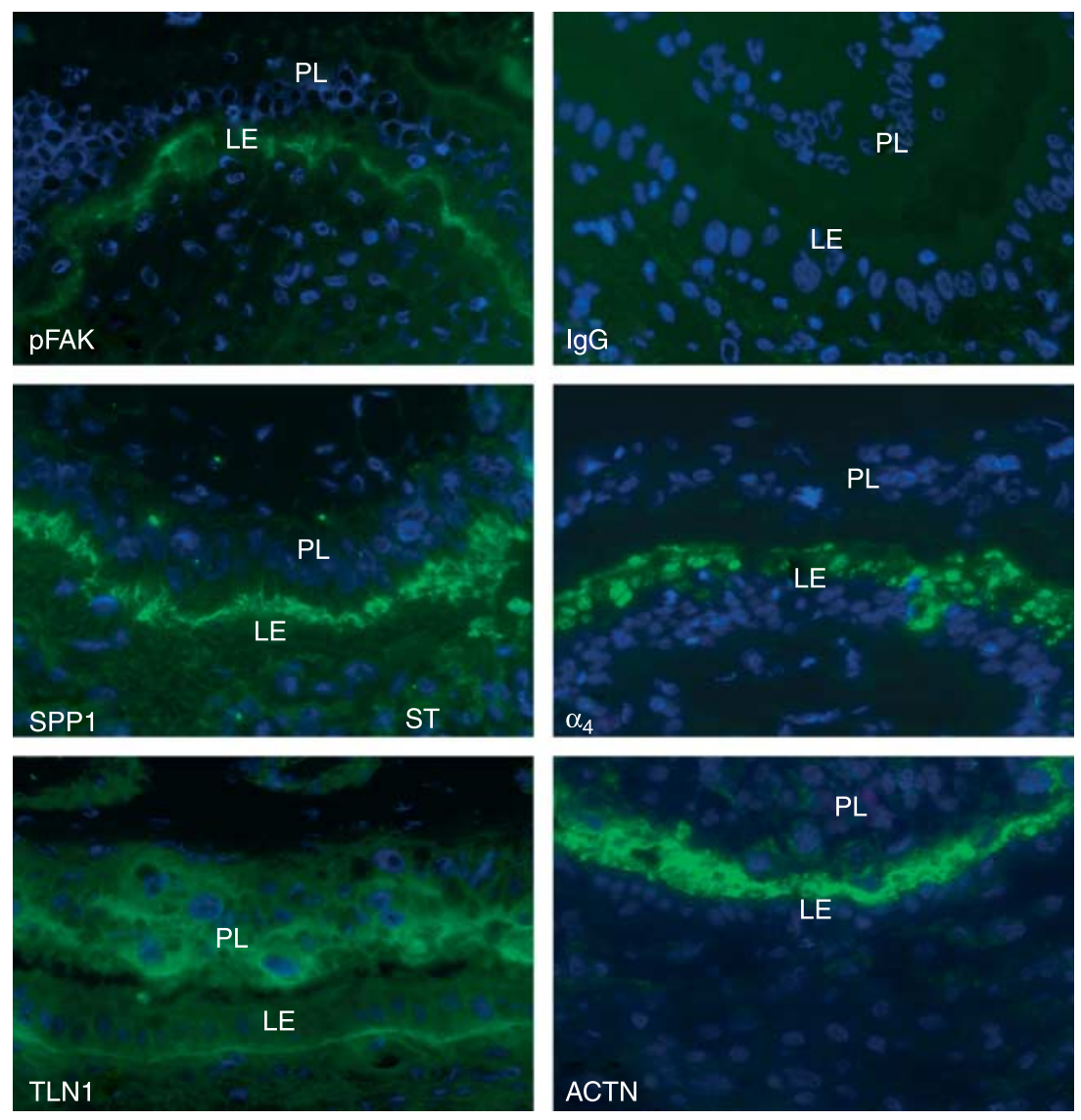

Figure $8 \mathrm{Immunofluorescence}$ analysis of cytoplasmic PTK2 at interplacentomal regions of day 120 gravid sheep maternal-conceptus interface. In this section, PTK2 staining is more prominent in the apical cytoplasm of uterine LE, but it was also detected in the apical cytoplasm of Tr. PTK2 is codistributed in LE and Tr with other focal adhesion proteins, including SPP1 at the maternal-conceptus interface, several integrins (including ITGA4 [ $\alpha 4]$ shown here), TLN1, and ACTN. Mouse $\lg G$ was used as the negative control for PTK2. Width of each field is $540 \mu \mathrm{m}$. demonstrating a requirement for $\mathrm{Tr}$ attachment to LE; and aggregates increase in number and size through day 120 of pregnancy. Interestingly, no accumulation of ITGB3 was observed even though ITGB3 is a prominent component of the maternal-conceptus interface during the peri-implantation period in sheep (Johnson et al. 2001). The developmental regulation of integrin expression or 'integrin switching' in conceptus and endometrial cells during implantation and placentation in rodents and human has been well documented (Damsky et al. 1994, Armant 2005, Kayisli et al. 2005), and the present results provide an in vivo correlate in sheep. The elevated expression of $\alpha_{v} \beta_{1}, \alpha_{v} \beta_{5}, \alpha_{4} \beta_{1}$, and $\alpha_{5} \beta_{1}$ receptors and loss of the $\alpha_{v} \beta_{3}$ integrin from the apical surface of interacting epithelial cells provide aggregates of receptors capable of binding both RGD and non-RGD containing ECM proteins to form focal adhesions at the maternal-conceptus interface.

In some regions of the interplacentomal interface, greater subunit aggregation was seen on the maternal side; in other regions it was predominant on the placental side, whereas in some others, both maternal and placental epithelia exhibited prominent focal adhesions. However, by day 120 of pregnancy, extensive focal adhesions were seen along most of the maternalconceptus interface. These variable focal adhesion patterns are likely due to anisotropic assembly of focal adhesions caused by regional differences and/or changing tensile, compression, and shear forces on either side of the interface that result from dynamic responses to changes in maternal posture, locomotion, and/or position of the fetus. As highly dynamic mechanosensing devices, focal adhesions are capable of rapidly responding to local force by increased assembly, and to relaxation of force by disassembly (Riveline et al. 2001, Bershadsky et al. 2006). It has recently been demonstrated that biological forces stabilize the high-affinity conformation of integrin subunits (Astrof et al. 2006). Based on these data, it is tempting to speculate that integrins within prominent assemblies of focal contacts are likely to exist in a high-affinity state, being maintained by the same mechanical forces that initiated integrin clustering and focal adhesion assembly.

The individual size, extent, and cellular distribution of the integrin aggregates that increase along the maternalconceptus interface during pregnancy indicates that the ECM mechanosensor(s) are highly rigid based on the observations of differences in focal adhesion structure in cells grown on matrices of different stiffness and thickness, as well as an understanding of the rigidity sensing components of focal adhesions (Vogel \& Sheetz 2006). Both elasticity/rigidity and thickness of the ECM 
play a key role in the growth of focal adhesions (Nicolas \& Safran 2006); the total force transmitted by focal adhesions is proportional to their surface area (Balaban et al. 2001). Furthermore, the apical expression of integrin receptors in endometrial LE and Tr cells highlights the differences in distribution of ECM surrounding epithelial cells. The formation of large integrin receptor aggregates at the apical surface of epithelial cells is novel as the distribution of the ECM and apical accumulation of activated integrins is strikingly similar to the organization of activated integrins and ECM at the basal surface of cultured cells grown on a rigid 2D matrix.

The placentomes, which provide hematotrophic support to the fetus and placenta, exhibited diffuse immunoreactivity for ITGAV, ITGA4, ITGA5, ITGB1, and ITGB3, but not ITGB5 compared with interplacentomal regions. The fetal side of the placentome consists of syncytial plaques derived from the fusion of binucleate Tr cells with uterine LE cells as well as each other that are thrown into tortuous interdigitating folds that separate the maternal caruncular and fetal cotelydonary vasculature. The highly folded syncytial $\mathrm{Tr}$ in the placentome, which is in contact with the ECM of underlying maternal and conceptus basal lamina, does not appear to be a major site of force transmission. This may be due to extensive folding at this interface or reduced rigidity of the maternal and fetoplacental basal laminas.

\section{SPP1 and LGALS15 are potential ECM mechanosensors at the maternal-conceptus interface}

The present results indicate that SPP1 and LGALS15, but not $\mathrm{FN}$ or $\mathrm{VN}$, are potential mechanosensors at the maternal-conceptus interface. Large accumulations of SPP1 protein, which form a thick matrix along with lesser amounts of LGALS15, were present at the interface between uterine and placental epithelia that were actively forming focal adhesions in response to binding ECM ligand. In contrast to the best-studied ECM mechanosensor, FN (reviewed in Vogel 2006), the mechanosensory functions of SPP1 and LGALS15 have not been examined in detail, although the diverse functions of these proteins suggest they could play such a role (reviewed in Denhardt \& Guo 1993, Butler et al. 1996, Weber \& Cantor 1996, Sodek et al. 2000, Johnson et al. 2003a, Farmer et al. 2008).

We previously reported that a $45 \mathrm{kDa}$ form of SPP1, with increased cell adhesion properties compared with full-length SPP1 (Agnihotri et al. 2001), is secreted by uterine glands under the influence of progesterone into the uterine lumen in sheep during pregnancy (Johnson et al. 2000), and is increasingly deposited at the maternal-conceptus interface throughout pregnancy in sheep (Johnson et al. 2001) and other mammals (Johnson et al. 1999a, 1999b, Apparao et al. 2001, Garlow et al. 2002, Joyce et al. 2005, White et al. 2006). SPP1 is a monomer of 278 amino acids, which undergoes extensive posttranslational modification including phosphorylation, glycosylation, and cleavage by thrombin, MMP3, and MMP7, resulting in molecular mass variants ranging from 24 to $75 \mathrm{kDa}$ (Johnson et al. 1999a, 1999b, Agnihotri et al. 2001), and a predicted secondary structure has eight $\alpha$-helices and six $\beta$-sheet segments. The full-length protein is flexible in solution and contains recognition sequences that confer the ability to potentially connect multiple binding partners, including at least nine different integrins via RGD and cryptic nonRGD-binding sites, CD44, MMP3, and factor $\mathrm{H}$ (Fisher et al. 2001). SPP1 is also capable of dimerization and transglutaminase-mediated cross-linking (Prince et al. 1991, Kaartinen et al. 1999) and is a widely distributed ECM molecule found in association with cell types ranging from immune cells, to epithelia, and to bone (Denhardt \& Guo 1993, Butler et al. 1996, Weber \& Cantor 1996).

Therefore, SPP1 has a spectrum of stiffness or rigidity as a consequence of tissue-specific posttranslational modifications. This may account for the differences in the distribution of different SPP1 protein forms detected in subepithelial stroma versus the maternal-conceptus interface (Johnson et al. 2003c). The flexible full-length $70 \mathrm{kDa}$ SPP1 protein was detected in the subepithelial stroma in pregnant animals and highly upregulated in the gravid horn by day 40 of pregnancy. By contrast, the $45 \mathrm{kDa}$ form of SPP1 present along the maternalconceptus interface is an ECM ligand for the $\alpha_{v} \beta_{1}$, $\alpha_{v} \beta_{5}$, and $\alpha_{5} \beta_{1}$ receptors present on uterine LE and $\operatorname{Tr}$ cells recognize the RGD sequence. It is only this $45 \mathrm{kDa}$ form of SPP1 that supports the $\alpha_{4} \beta_{1}$ integrin-mediated adhesion and attachment to dual cryptic non-RGDbinding sites (ELVTDFPTDLPAT and SVVYGLR; Bayless \& Davis 2001). While FN is also capable of binding the same integrins, it was barely detectable at this interface. Therefore, the dramatic aggregation of the integrins in LE and $\operatorname{Tr}$ cells suggests a very rigid ECM substrate bridging these cells which is most likely provided by the $45 \mathrm{kDa}$ SPP1 fragment.

Like SPP1, LGALS15 is a novel progesterone-induced secreted protein that is first produced by the endometrial LE during pregnancy in sheep. Although LGALS15 is not synthesized by the conceptus $\mathrm{Tr}$, LGALS15 protein is present on conceptus $\operatorname{Tr}$ and within both $\operatorname{Tr}$ and endometrial LE, often in the form of crystalline inclusions (Gray et al. 2004). Based on the nucleotide sequence of the coding region, ovine endometrial LGALS15 is composed of 137 amino acids predicted to yield a $15.4 \mathrm{kDa}$ protein and displays the greatest similarity to galectin 13 (LGALS13, also known as placental tissue protein 13; Bohn et al. 1983). Recent studies have indicated that LGALS15 can mediate attachment of $\mathrm{Tr}$ cells and cause the formation of focal adhesions via the binding and activation of the integrins present at the maternal-conceptus interface in sheep (Farmer et al. 2008). While the secondary structure of LGALS15 has 
not been identified, its most closely related family member, LGALS13, like other 'prototype galectins', it is a multimodular protein consisting of a five- or sixstranded $\beta$-sheets joined by two $\alpha$-helices (Visegrady et al. 2001). The developmentally regulated expression of LGALS15 and capacity for potential interactions with both carbohydrates and integrins suggests a potentially important factor influencing cell-cell and cell-matrix interactions at the maternal-conceptus interface during the peri-implantation period. Like the $45 \mathrm{kDa}$ form of SPP1, LGALS15 may also provide a suitable ECM substrate for bridging these cells. However, since the majority of LGALS15 immunostaining was sequestered within the $\mathrm{Tr}$ in gravid uterine horns later in pregnancy, we hypothesize that later in pregnancy SPP1, rather than LGALS15, provides a substantial and rigid ECM at the maternal-conceptus interface that interacts with integrins to promote assembly of large focal adhesions that adhere uterine LE to conceptus Tr cells for mechanosensation and signal generation essential to placentation in sheep.

\section{Cytoplasmic mechanosensors and a signal generator at the maternal-conceptus interface}

The cytoskeletal adaptor proteins TLN1, ACTN, and VCL can physically couple actin filaments to $\beta$-integrins. Both TLN1 and ACTN bind directly to the cytoplasmic tail of $\beta$-integrins as well as actin filaments to provide direct mechanical coupling between integrins and the cytoskeleton (Critchley 2000). Structurally, ACTN and VCL are thought to function as cytoplasmic mechanosensors. Unlike force-bearing proteins in the ECM, which consist mostly of tandem $\beta$-sheet motifs, ACTN and VCL are characterized by $\alpha$-helical bundles that require less force for stretching (Vogel 2006). The results of the present studies suggest that ACTN, which strengthens forcedependent adhesion, is the dominant cytoplasmic mechanosensor in focal adhesions present in LE and $\mathrm{Tr}$ cells at the maternal-conceptus interface. The robust accumulation of ACTN compared with TLN1 provides further support for the presence of a rigid ECM and large forces at this interface based upon the direct role of ACTN in force-dependent reinforcement and the strain hardening of F-actin networks that are dependent on the amount of bound ACTN leading to enhanced cell stiffness (Xu et al. 2000).

ACTN is also associated with cadherin-based adherens junctions in epithelial cells that are important players in mechanotransduction. Indeed, crosstalk between focal adhesions and adherens junctions has been reported (Chen et al. 2004). However, aggregation of ACTN at focal adhesions in LE and Tr was shown to be distinct from the involvement of ACTN in the adherens junctions, as recruitment of ACTN to apical LE focal adhesions did not appear to alter adherens junction integrity based upon the absence of changes in $\mathrm{CDH} 1$ along the lateral border of LE and Tr that develop apical focal adhesions.

Additional evidence for in vivo focal adhesion assembly is the accumulation of autophosphorylated pY397-PTK2 (pPTK2) in the apical compartments of LE and $\operatorname{Tr}$ cells. pPTK2 accumulates and localizes to focal adhesions (Schaller et al. 1994, Katz et al. 2003). Interestingly, pY397-PTK2 has been characterized to be a marker of cytotrophoblast invasion in human placenta (Ilic et al. 2001), and SPP1 is a progesteroneregulated marker of cytotrophoblasts (Omigbodun et al. 1995, 1997). Phospho-PTK2 has been implicated in the mechanosensing response. PTK2 null cells cannot detect differences in ECM rigidity (Wang et al. 2001), and PTK2 becomes phosphorylated when mechanical stress is applied to smooth muscle and endothelial cells (Yano et al. 1996, Tang et al. 1999). Significantly, pPTK2 is absent from most of the length of 3D matrix adhesions in fibroblasts within ECM or cultured in collagen gels (Cukierman et al. 2001). This is consistent with regulation in 3D matrices since these matrices are far less rigid than 2D matrices, as well as the observation in the present study that PPTK2 was barely detectable in areas where integrins and ECM and cytoskeletal mechanosensory proteins accumulated within the subepithelial stroma and placentomes. Therefore, these data suggest that the in vivo focal adhesions that develop at the interplacentomal maternal-conceptus interface are more closely related to the $2 \mathrm{D}$ in vitro focal adhesions that develop on rigid planar ECM.

There are two caveats to these data. 1) As focal adhesions are dynamic structures that respond to force, it was not possible in the current study to maintain all of the balanced and unbalanced forces along the uterine wall during tissue isolation and processing. To address this issue, ovariohysterectomy and tissue processing were performed as rapidly as possible. 2) Available combinations of validated rabbit polyclonal and mouse monoclonal antibodies have limited our options for colocalization studies in frozen sections of pregnant sheep uterus, and therefore definitive colocalization of focal adhesion proteins were not performed in these studies. However, we have previously shown overlapping localization of ITGAV, ITGB5, ACTN, and SPP1 in sequential serial sections of day 40 interplacentomal regions of implantation sites, which supports the argument for activation of integrins at these implantation sites in vivo (Johnson et al. 2003a). Future studies will explore colocalization of specific focal adhesion-associated signaling pathway components at high spatial resolution with confocal/multiphoton microscopy combined with spectral analysis and/or FRET to verify protein-protein interactions as additional combinations of validated antibodies derived in multiple species are identified.

In summary, tissue compartments within the uterine wall during pregnancy in sheep provide an excellent 
in vivo model system to investigate mechanotransduction along with the role of focal adhesions in this process. The results presented here are consistent with the activation of uterine LE and $\operatorname{Tr} \alpha_{v} \beta_{1}, \alpha_{v} \beta_{5}, \alpha_{4} \beta_{1}$, and $\alpha_{5} \beta_{1}$ integrin receptors (but not $\alpha_{v} \beta_{3}$ ) to form robust focal adhesions in response to binding ligands associated at the apical surfaces of these cells, and provide the first direct in vivo evidence for functional roles of integrins in signaling between conceptus and maternal tissues during placentation. Furthermore, the development of large focal adhesions appears to reflect adaptation of the placenta to tensile, compression, and shear loads imposed by increasing fetal and placental growth, as their assembly into extended grouped focal adhesions increases at the maternal-conceptus interface as pregnancy progresses. We hypothesize that the cooperative binding of multiple integrins to a rigid ECM, consisting of large accumulations of integrin-binding $45 \mathrm{kDa}$ form of SPP1, forms an adhesive mosaic to maintain a tight connection between uterine and placental surfaces along regions of true epitheliochorial placentation in sheep. Lastly, differences in the organization of in vivo focal adhesions in uterine myometrial and stromal layers as well as at the maternal-conceptus interface reveal the development of markedly different elastic microenvironments in tissue-level compartments of the uterus during pregnancy in sheep.

\section{Materials and Methods}

\section{Animals}

Experimental procedures complied with the Guide for Care and Use of Agricultural Animals in Research and Teaching, and were approved by the Texas A\&M University Institutional Animal Care and Use Committee. Mature western-range ewes of primarily Suffolk breeding were observed daily for estrous behavior. Following at least two estrous cycles of normal duration (16-18 days), ewes were assigned randomly on day 0 (estrus/mating) to cyclic or pregnant status. Four ewes each were ovariohysterectomized on days 15 of the cycle or pregnancy. An additional 12 ewes were surgically prepared to limit pregnancy to one uterine horn. Briefly, the ovary ipsilateral to the right uterine horn was removed and a double ligature was placed at the base of the uterine horn at the bifurcation. At the following estrus (day 0 ), sheep were mated to intact rams to generate gravid and non-gravid uterine horns in each bred sheep (Bazer et al. 1979). Sheep were ovariohysterectomized on days 40, 80, and 120 of pregnancy ( $n=4 /$ day, gestation length $\sim 147$ days). Several $1-1.5 \mathrm{~cm}$ sections of uterine wall from the middle of each horn from cyclic and pregnant ewes, including placentomes and interplacentomal regions of gravid horns, were snap frozen in Tissue-Tek O.C.T. compound (Miles, Oneata, NY, USA). Attempts were made to minimize the interval from ovariohysterectomy to freezing tissue due to separation of some placental membranes and interplacentomal endometrium within 10-30 min following surgical removal of the uterus.

\section{Immunofluorescence staining}

Antibodies used for immunostaining included the following: rabbit anti- $\alpha_{v}(\# A B 1930), \alpha_{4}(\# A B 1924), \alpha_{5}$ (\#AB1928), $\beta_{1}$ $(\# A B 1952), \beta_{3}(\# A B 1932), \beta_{5}$ (\#AB1926) integrin subunits, mouse anti- $\alpha_{v} \beta_{3}$ integrin heterodimer (\#MAB 1976Z), rabbit anti-laminin (\#AB19012), rabbit anti-VN (\#AB1903), and mouse anti-FN (\#MAB88916) from Chemicon (Temecula, CA, USA); mouse anti-talin clone 8d4 (\#T3287), rabbit anti-ACTN (\#A2543), normal rabbit IgG (\#15006), and normal mouse IgG (\#15381) from Sigma Aldrich; and mouse anti-FAK (pY397, \#611806) and mouse anti-CDH1 (\#610182) from BD Biosciences (San Jose, CA, USA). Rabbit anti-human recombinant SPP1 IgG (LF-123 and LF-124) was a gift from Dr Larry Fisher, National Institutes of Health. The LF-124 antibody recognizes the amino half of recombinant human SPP1 ending at the thrombin cleavage site and contains all integrin-binding sites; LF-123 targets the carboxyl half of the molecule and recognizes full-length SPP1, but not the amino half of the cleaved protein containing integrin-binding sites (Fisher et al. 1995). Rabbit anti-ovine LGALS15 IgG was prepared as described previously (Lewis et al. 2007).

Proteins were localized in frozen uterine tissue sections by immunofluorescence staining as described previously (Johnson et al. 1999a, 1999b). The sections were fixed in $-20^{\circ} \mathrm{C}$ methanol, permeabilized, and washed with PBS containing $0.3 \% \mathrm{vol} / \mathrm{vol}$ Tween 20 (rinse solution), blocked in $10 \%$ normal goat serum, and incubated overnight at $4{ }^{\circ} \mathrm{C}$ with primary antibody at a dilution optimized for each antibody. Immunoreactive proteins were detected using the appropriate Alexa Fluor 594- or Alexa Fluor 488-conjugated secondary antibodies for $1 \mathrm{~h}$ at room temperature at a dilution of 1:250. Slides were overlaid with a coverslip and ProLong antifade mounting reagent containing the nuclear counterstain DAPI (Invitrogen, Molecular Probes, Eugene, OR, USA).

ITGAV was localized with $\mathrm{CDH} 1$ in frozen uterine cross sections by immunofluorescence staining as described previously (Muniz et al. 2006). Briefly, the sections were fixed, washed, and blocked as described above. After dipping in rinse solution at room temperature, the sections were incubated overnight at $4{ }^{\circ} \mathrm{C}$ with the initial primary antibody (mouse anti-Ecadherin). Following three washes with $4{ }^{\circ} \mathrm{C}$ rinse solution for $10 \mathrm{~min}$ each, the sections were incubated with the initial secondary antibody (Alexa 488-conjugated goat anti-mouse $\operatorname{lgG}$ ) for $4 \mathrm{~h}$ at room temperature, and washed with $4{ }^{\circ} \mathrm{C}$ rinse solution six times for $10 \mathrm{~min}$ each. The sections were then incubated overnight at $4{ }^{\circ} \mathrm{C}$ with the second primary antibody $\left(\right.$ rabbit anti- $\left.\alpha_{v}\right)$. Following six washes with $4{ }^{\circ} \mathrm{C}$ rinse solution for 10 min each, the sections were incubated with the second secondary antibody (Alexa 594-conjugated goat anti-rabbit lgG) for $2 \mathrm{~h}$ at $4{ }^{\circ} \mathrm{C}$, washed six times with $4{ }^{\circ} \mathrm{C}$ rinse solution for $10 \mathrm{~min}$ each, and dipped in distilled-deionized water. Slides were overlaid with antifade mounting reagent containing DAPI.

\section{Photomicrography}

Digital immunofluorescence images were evaluated using an Axioplan 2 microscope (Carl Zeiss, Thornwood, NY, USA) interfaced with an Axioplan HR digital camera and Axiovision 
4.3 software. For colocalization of proteins, camera settings were evaluated to confirm that no 'spectral bleed through' Alexa 488 signal was detectable in the Alexa 594 filter set and vice versa. Individual fluorophore images were recorded sequentially and evaluated in multiple fluorophore overlay images. Photographic plates were assembled using Adobe Photoshop CS2 (version 9.0, Adobe Systems Inc., San Jose, CA, USA).

\section{Declaration of interest}

The authors declare that there is no conflict of interest that could be perceived as prejudicing the impartiality of the research reported.

\section{Funding}

This research was funded, in part, by National Research Initiative Competitive Grants 2005-35203-16252 and 200600837 from the USDA Cooperative State Research, Education, and Extension Service as well as by a pilot project and core facilities of the Texas A\&M Center for Environmental and Rural Health (NIEHS P30 ES09106 and NIH-NCRR (1 S10 RR22532-01).

\section{Acknowledgements}

We thank members of the Center for Animal Biotechnology and Genomics, Texas A\&M University, for their contributions to the surgical preparation of the unilaterally pregnant sheep along with animal care and husbandry. We are grateful to Dr Larry Fisher of the National Institutes of Health for the gift of the LF123 and LF-124 antibodies to SPP1 used in this study.

\section{References}

Agnihotri R, Crawford HC, Haro H, Matrisian LM, Havrda MC \& Liaw L 2001 Osteopontin, a novel substrate for matrix metalloproteinase-3 (stromelysin-1) and matrix metalloproteinase-7 (matrilysin). Journal of Biological Chemistry 276 28261-28267.

Aplin JD 1997 Adhesion molecules in implantation. Reviews of Reproduction 2 84-93.

Apparao KB, Murray MJ, Fritz MA, Meyer WR, Chambers AF, Truong PR \& Lessey BA 2001 Osteopontin and its receptor alphavbeta(3) integrin are coexpressed in the human endometrium during the menstrual cycle but regulated differentially. Journal of Clinical Endocrinology and Metabolism 86 4991-5000.

Armant DR 2005 Blastocyts don't go it alone. Extrinsic signals fine-tune the intrinsic developmental program of trophoblast cells. Developmental Biology 280 260-280.

Astrof NS, Salas A, Shimaoka M, Chen J \& Springer TA 2006 Importance of force linkage in mechanochemistry of adhesion receptors. Biochemistry 45 15020-15028.

Balaban NQ, Schwarz US, Riveline D, Goichberg P, Tzur G, Sabanay I, Mahalu D, Safran S, Bershadsky A, Addadi L et al. 2001 Force and focal adhesion assembly: a close relationship studied using elastic micropatterned substrates. Nature Cell Biology 3 466-472.

Bayless KJ \& Davis GE 2001 Identification of dual alpha 4beta1 integrin binding sites within a 38 amino acid domain in the $\mathrm{N}$-terminal thrombin fragment of human osteopontin. Journal of Biological Chemistry 276 13483-13489.

Bazer FW, Roberts RM, Basha SM, Zavy MT, Caton D \& Barron DH 1979 Method for obtaining ovine uterine secretions from unilaterally pregnant ewes. Journal of Animal Science 49 1522-1527.
Bershadsky A, Kozlov M \& Geiger B 2006 Adhesion-mediated mechanosensitivity: a time to experiment, and a time to theorize. Current Opinion in Cell Biology 18 472-481.

Bohn H, Kraus W \& Winckler W 1983 Purification and characterization of two new soluble placental tissue proteins (PP13 and PP17). Oncodevelopmental Biology and Medicine 4 343-350.

Burghardt RC, Bowen JA, Newton GR \& Bazer FW 1997 Extracellular matrix and the implantation cascade in pigs. Journal of Reproduction and Fertility 52 151-164.

Burghardt RC, Johnson GA, Jaeger LA, Ka H, Garlow JE, Spencer TE \& Bazer FW 2002 Integrins and extracellular matrix proteins at the maternal-fetal interface in domestic animals. Cells, Tissues, Organs 172 202-217.

Butler WT, Ridall AL \& McKee MD 1996 Osteopontin. In Principals of Bone Biology, pp 167-181. Eds J Bilezikian, L Raisz \& G Rodan. New York: Academic Press, Inc.

Chen CS, Tan J \& Tien J 2004 Mechanotransduction at cell-matrix and cellcell contacts. Annual Review of Biomedical Engineering 6 275-302.

Coutifaris C, Omigbodun A \& Coukos G 2005 The fibronectin receptor alpha 5 integrin subunit is upregulated by cell-cell adhesion via a cyclic AMPdependent mechanism: implications for human trophoblast migration. American Journal of Obstetrics and Gynecology 192 1240-1253.

Critchley DR 2000 Focal adhesions - the cytoskeletal connection. Current Opinion in Cell Biology 12 133-139.

Cukierman E, Pankov R, Stevens DR \& Yamada KM 2001 Taking cell-matrix adhesions to the third dimension. Science 294 1661-1663.

Cukierman E, Pankov R \& Yamda KM 2002 Cell interactions with threedimensional matrices. Current Opinion in Cell Biology 14 633-639.

Damsky CH, Librach C, Lim KH, Fitzgerald ML, McMaster MT, Janatpour M, Zhou Y, Logan SK \& Fisher SJ 1994 Integrin switching regulates normal trophoblast invasion. Development 120 3657-3666.

Denhardt DT \& Guo X 1993 Osteopontin: a protein with diverse functions. FASEB Journal 7 1475-1482.

Eddinger TJ, Schiebout JD \& Swartz DR 2007 Adherens junction-associated protein distribution differs in smooth muscle tissue and acutely isolated cells. American Journal of Physiology. Gastrointestinal and Liver Physiology 292 G684-G697.

Engler AJ, Sen S, Sweeney HL \& Discher DE 2006 Matrix elasticity directs stem cell lineage specification. Cell 126 677-689.

Farmer JL, Burghardt RC, Jousan FD, Hansen PJ, Bazer FW \& Spencer TE 2008 Galectin 15 (LGALS15) functions in trophectoderm migration and attachment. FASEB Journal 22 548-560.

Fisher LW, Stubbs JT III \& Young MF 1995 Antisera and cDNA probes to human and certain animal model bone matrix noncollagenous proteins. Acta Orthopaedica Scandinavica 266 61-65.

Fisher LW, Torchia DA, Fohr B, Young MF \& Fedarko NS 2001 Flexible structures of SIBLING proteins, bone sialoprotein and osteopontin. Biochemical and Biophysical Research Communications 280 460-465.

Galbraith CG, Yamada KM \& Sheetz MP 2002 The relationship between force and focal complex development.. Journal of Cell Biology 159 695-705.

Garlow JE, Ka H, Johnson GA, Burghardt RC, Jaeger LA \& Bazer FW 2002 Analysis of osteopontin at the maternal-placental interface in pigs. Biology of Reproduction 266 718-725.

Geiger B \& Bershadsky A 2002 Exploring the neighborhood: adhesion coupled cell mechanosensors. Cell 110 139-142.

Giannone G \& Sheetz MP 2006 Substrate rigidity and force define form through tyrosine phosphatase and kinase pathways. Trends in Cell Biology 16 213-223.

Gray CA, Adelson DL, Bazer FW, Burghardt RC, Meeusen EN \& Spencer TE 2004 Discovery and characterization of an epithelial-specific galectin in the endometrium that forms crystals in the trophectoderm. PNAS 101 7982-7987.

Hinz B 2007 Formation and function of the myofibroblast during tissue repair. Journal of Investigative Dermatology 127 526-537.

Ilic D, Genbacev O, Jin F, Caceres E, Almeida EA, Bellingard-Dubouchaud V, Schaefer EM, Damsky CH \& Fisher SJ 2001 Plasma membraneassociated pY397FAK is a marker of cytotrophoblast invasion in vivo and in vitro. American Journal of Pathology 159 93-108.

Illera MJ, Cullinan E, Gui Y, Yuan L, Beyler SA \& Lessey BA 2000 Blockade of the alpha(v)beta(3) integrin adversely affects implantation in the mouse. Biology of Reproduction 62 1285-1290. 
Illera MJ, Lorenzo PL, Gui YT, Beyler SA, Apparao KB \& Lessey BA 2003 A role for alphavbeta3 integrin during implantation in the rabbit model. Biology of Reproduction 68 766-771.

Jaeger LA, Spiegel AK, Ing NH, Johnson GA, Bazer FW \& Burghardt RC 2005 Functional effects of transforming growth factor beta (TGF $\beta$ ) on adhesive properties of porcine trophectoderm. Endocrinology $\mathbf{1 4 6}$ 3933-3942.

Johnson GA, Spencer TE, Burghardt RC \& Bazer FW 1999a Ovine osteopontin: I. Cloning and expression of messenger ribonucleic acid in the uterus during the periimplantation period. Biology of Reproduction 61 884-891.

Johnson GA, Burghardt RC, Spencer TE, Newton GR, Ott TL \& Bazer FW $1999 b$ Ovine osteopontin: II. Osteopontin and $\alpha_{v}, \beta_{3}$ integrin expression in the uterus and conceptus during the peri-implantation period. Biology of Reproduction 61 892-899.

Johnson GA, Spencer TE, Burghardt RC, Taylor KM, Gray CA \& Bazer FW 2000 Progesterone modulation of osteopontin gene expression in the ovine uterus. Biology of Reproduction 62 1315-1321.

Johnson GA, Bazer FW, Jaeger LA, Ka H, Garlow JE, Pfarrer C, Spencer TE \& Burghardt RC 2001 Muc-1, integrin, and osteopontin expression during the implantation cascade in sheep. Biology of Reproduction 65 820-828.

Johnson GA, Burghardt RC, Bazer FW \& Spencer TE 2003a Osteopontin: roles in implantation and placentation. Biology of Reproduction 69 1458-1471.

Johnson GA, Burghardt RC, Joyce MM, Spencer TE, Bazer FW, Pfarrer C \& Gray CA 2003b Osteopontin expression in uterine stroma indicates a decidualization-like differentiation during ovine pregnancy. Biology of Reproduction 68 1951-1958.

Johnson GA, Burghardt RC, Joyce MM, Spencer TE, Bazer FW, Gray CA \& Pfarrer C 2003c Osteopontin is synthesized by uterine glands and a 45-kDa cleavage fragment is localized at the uterine-placental interface throughout ovine pregnancy. Biology of Reproduction 69 92-98.

Joyce MM, Gonzalez JF, Lewis S, Woldesenbe S, Burghardt RC, Newton GR \& Johnson GA 2005 Caprine uterine and placental osteopontin expression is distinct among epitheliochorial implanting species. Placenta 26 160-170.

Kaartinen MT, Pirhonen A, Linnala-Kankkunen A \& Maenpaa PH 1999 Cross-linking of osteopontin by tissue transglutaminase increases its collagen binding properties. Journal of Biological Chemistry $\mathbf{2 7 4}$ $1729-1735$

Katz BZ, Zamir E, Bershadsky A, Kam Z, Yamada KM \& Geiger B 2000 Physical state of the extracellular matrix regulates the structure and molecular composition of cell-matrix adhesions. Molecular Biology of the Cell 11 1047-1060.

Katz BZ, Romer L, Miyamoto S, Volberg T, Matsumoto K, Cukierman E, Geiger B \& Yamada KM 2003 Targeting membrane-localized focal adhesion kinase to focal adhesions: roles of tyrosine phosphorylation and SRC family kinases. Journal of Biological Chemistry 278 29115-29120.

Kayisli UA, Korgun ET, Akkoyunlu G, Arici A \& Demir R 2005 Expression of integrin alpha5 and integrin beta 4 and their extracellular ligands fibronectin and laminin in human decidua during early pregnancy and its sex steroid-mediated regulation. Acta Histochemica 107 173-185.

Kimber SJ 2000 Cell biology of implantation and placentation. Introduction. Seminars in Cell and Developmental Biology 11 61-65.

Larsen M, Artym VV, Green JA \& Yamada KM 2006 The matrix reorganized: extracellular matrix remodeling and integrin signaling. Current Opinion in Cell Biology 18 463-471.

Lessey BA 2002 Adhesion molecules and implantation. Journal of Reproductive Immunology 55 101-112.

Lewis SK, Farmer JL, Burghardt RC, Newton GR, Johnson GA, Adelson DL, Bazer FW \& Spencer TE 2007 Galectin 15 (LGALS15): a gene uniquely expressed in the uteri of sheep and goats that functions in trophoblast attachment. Biology of Reproduction 77 1027-1036.

Li Y, Gallant C, Malek S \& Morgan KG 2007 Focal adhesion signaling is required for myometrial ERK activation and contractile phenotype switch before labor. Journal of Cellular Biochemistry 100 129-140.

MacPhee DJ \& Lye SJ 2000 Focal adhesion signaling in the rat myometrium is abruptly terminated with the onset of labor. Endocrinology 141 274-283.
MacPhee DJ, Mostachfi H, Han R, Lye SJ, Post M \& Caniggia I 2001 Focal adhesion kinase is a key mediator of human trophoblast development. Laboratory Investigation 81 1469-1483.

Miyamoto S, Teramoto H, Coso OA, Gutkind JS, Burbelo PD, Akiyama SK \& Yamada KM 1995 Integrin function: molecular hierarchies of cytoskeletal and signaling molecules. Journal of Cell Biology 131 791-805.

Muniz JJ, Joyce MM, Taylor JD, Burghardt JR, Burghardt RC \& Johnson GA 2006 Glycosylation dependent cell adhesion molecule 1 (GlyCAM-1)like protein and L-selectin expression in sheep interplacentomal and placentomal endometrium. Reproduction 131 751-761.

Nicolas A \& Safran SA 2006 Limitation of cell adhesion by the elasticity of the extracellular matrix. Biophysical Journal 911 61-73.

Omigbodun A, Daiter E, Walinsky D, Fisher L, Young M, Hoyer J \& Coutifaris C 1995 Regulated expression of osteopontin in human trophoblasts. Annals of the New York Academy of Sciences $\mathbf{7 6 0}$ 346-349.

Omigbodun A, Ziolkiewicz P, Tessler C, Hoyer JR \& Coutifaris C 1997 Progesterone regulates osteopontin expression in human trophoblasts: a model of paracrine control in the placenta? Endocrinology 138 4308-4315.

Parast MM, Aeder S \& Sutherland AE 2001 Trophoblast giant-cell differentiation involves changes in cytoskeleton and cell motility. Developmental Biology 230 43-60.

Prince CW, Dickie D \& Krumdieck CL 1991 Osteopontin, a substrate for transglutaminase and factor XIII activity. Biochemical and Biophysical Research Communications 177 1205-1210.

Quenby S, Anim-Somuah M, Kalumbi C, Farquharson R \& Aplin JD 2007 Different types of recurrent miscarriage are associated with varying patterns of adhesion molecule expression in endometrium. Reproductive Biomedicine Online 14 224-234.

Rehfeldt F, Engler AJ, Eckhardt A, Ahmed F \& Discher DE 2007 Cell responses to the mechanochemical microenvironment - implications for regenerative medicine and drug delivery. Advanced Drug Delivery Reviews 59 1329-1339.

Riveline D, Zamir E, Balaban NQ, Schwarz US, Ishizaki T, Narumiya S, Kam Z, Geiger B \& Bershadsky AD 2001 Focal contacts as mechanosensors: externally applied local mechanical force induces growth of focal contacts by an mDia1-dependent and ROCK-independent mechanism. Journal of Cell Biology 153 1175-1186.

Roskelley CD \& Bissell MJ 1995 Dynamic reciprocity revisited: a continuous, bidirectional flow of information between cells and the extracellular matrix regulates mammary epithelial cell function. Biochemistry and Cell Biology 73 391-397.

Sastry SK \& Burridge K 2000 Focal adhesions: a nexus for intracellular signaling and cytoskeletal dynamics. Experimental Cell Research $\mathbf{2 6 1}$ 25-36.

Schaller MD, Hildebrand JD, Shannon JD, Fox JW, Vines RR \& Parsons JT 1994 Autophosphorylation of the focal adhesion kinase, pp125FAK, directs SH2-dependent binding of pp60src. Molecular Biology of the Cell 14 1680-1688.

Shynlova O, Mitchell JA, Tsampalieros A, Langille BL \& Lye SJ 2004 Progesterone and gravidity differentially regulate expression of extracellular matrix components in the pregnant rat myometrium. Biology of Reproduction 70 986-992.

Shynlova O, Williams SJ, Draper H, White BG, Macphee DJ \& Lye SJ 2007 Uterine stretch regulates temporal and spatial expression of fibronectin protein and its alpha 5 integrin receptor in myometrium of unilaterally pregnant rats. Biology of Reproduction 77 880-888.

Sodek J, Ganss B \& McKee MD 2000 Osteopontin. Critical Reviews in Oral Biology and Medicine 11 279-303.

Tang D, Mehta D \& Gunst SJ 1999 Mechanosensitive tyrosine phosphorylation of paxillin and focal adhesion kinase in tracheal smooth muscle. American Journal of Physiology 276 C250-C258.

Visegrady B, Than NG, Kilar F, Sumegi B, Than GN \& Bohn H 2001 Homology modelling and molecular dynamics studies of human placental tissue protein 13 (galectin-13). Protein Engineering 14 875-880.

Vogel V 2006 Mechanotransduction involving multimodular proteins: converting force into biochemical signals. Annual Review of Biophysics and Biomolecular Structure 35 459-488. 
Vogel V \& Sheetz M 2006 Local force and geometry sensing regulate cell functions. Nature Reviews. Molecular Cell Biology 7 265-275.

Wang HB, Dembo M, Hanks SK \& Wang Y 2001 Focal adhesion kinase is involved in mechanosensing during fibroblast migration. PNAS $\mathbf{9 8}$ 11295-11300.

Weber GF \& Cantor H 1996 The immunology of Eta-1/osteopontin. Cytokine and Growth Factor Reviews 7 241-248.

White FJ, Burghardt RC, Hu J, Joyce MM, Spencer TE \& Johnson GA 2006 Secreted phosphoprotein 1 (osteopontin) is expressed by stromal macrophages in cyclic and pregnant endometrium of mice, but is induced by estrogen in luminal epithelium during conceptus attachment for implantation. Reproduction 132 919-929.

Williams SJ, White BG \& MacPhee DJ 2005 Expression of alpha5 integrin (Itga5) is elevated in the rat myometrium during late pregnancy and labor: implications for development of a mechanical syncytium. Biology of Reproduction 72 1114-1124.
Wozniak MA, Modzelewska K, Kwong L \& Keely PJ 2004 Focal adhesion regulation of cell behavior. Biochimica et Biophysica Acta 1692 103-119.

Xu J, Tseng Y \& Wirtz D 2000 Strain hardening of actin filament networks. Regulation by the dynamic cross-linking protein alpha-actinin. Journal of Biological Chemistry 275 35886-35892.

Yano Y, Geibel J \& Sumpio BE 1996 Tyrosine phosphorylation of pp125FAK and paxillin in aortic endothelial cells induced by mechanical strain. American Journal of Physiology 271 C635-C649.

Received 14 July 2008

First decision 20 August 2008

Revised manuscript received 23 November 2008

Accepted 5 December 2008 